\title{
Human $\beta$-defensin-3 inhibits migration of colon cancer cells via downregulation of metastasis-associated 1 family, member 2 expression
}

\author{
SATOKO URAKI ${ }^{1}$, KAZUSHI SUGIMOTO $^{1,2}$, KATSUYA SHIRAKI $^{1}$, MASAHIKO TAMEDA $^{1,2}$, \\ YUJI INAGAKI ${ }^{1}$, SUGURU OGURA ${ }^{1}$, CHIKA KASAI $^{1}$, KEIICHIRO NOJIRI $^{1}$, MISAO YONEDA ${ }^{1}$, \\ NORIHIKO YAMAMOTO $^{1}$, YOSHIYUKI TAKEI ${ }^{3}$, TSUTOMU NOBORI ${ }^{2}$ and MASAAKI ITO ${ }^{1}$ \\ ${ }^{1}$ First Department of Internal Medicine, ${ }^{2}$ Department of Molecular and Laboratory Medicine \\ and ${ }^{3}$ Department of Gastroenterology, Mie University School of Medicine, Tsu, Japan
}

Received March 18, 2014; Accepted May 7, 2014

DOI: $10.3892 / \mathrm{ijo} .2014 .2507$

\begin{abstract}
The innate immune system plays an important role as the first line of defense against many types of microbes. Accumulating reports suggest that human $\beta$-defensins (hBDs) are expressed by and have certain roles in some cancer cells. In this study, we investigated the roles of hBD-3 in colon cancer cells. The expression of hBD-3 was examined by reverse transcriptase-polymerase chain reaction analysis of colon cancer cell lines and immunohistochemical staining of colon cancer tissues. The effect of hBD-3 on proliferation of colon cancer was assessed using the MTT assay and a real-time cell analyzer, and the effect of hBD-3 on the migration of colon cancer cells was also examined. The results showed that hBD-3 is not expressed in colon cancer cells but is produced by tumorinfiltrating monocytes. Migration of colon cancer cells was significantly inhibited by hBD-3 in a dose-dependent manner, although proliferation of colon cancer cells was not affected by administration of hBD-3. Moreover, reduced expression of metastasis-associated 1 family, member 2 (MTA2) mRNA in colon cancer cells was associated with exposure to hBD-3. In conclusion, progression of colon cancer was inhibited by hBD-3 in a paracrine fashion. Therefore, hBD-3 may be a potent new agent for treating colon cancer.
\end{abstract}

\section{Introduction}

The innate immune system plays an important role as the first line of defense against bacteria, fungi, and viruses before adaptive immunity to these potential pathogens is developed. Mucosal cells in particular produce many types of antimicrobial

Correspondence to: Dr Kazushi Sugimoto, First Department of Internal Medicine, Department of Molecular and Laboratory Medicine, Mie University School of Medicine, 2-174 Edobashi, Tsu, Mie 514-8507, Japan

E-mail:kazushi@clin.medic.mie-u.ac.jp

Key words: human $\beta$-defensin-3, colon cancer, cell migration, MTA2 peptides that prevent invasion or growth of pathogens. The $\alpha$ - and $\beta$-defensins are classes of cysteine-rich, cationic antimicrobial peptides $(1,2)$. To date, six human $\alpha$-defensins and 28 human $\beta$-defensins (hBDs) have been identified $(3,4)$. Some hBDs are constitutively expressed in epithelial cells, whereas expression of hBD-2 and hBD-3 is induced by microbial products or inflammatory stimuli $(5,6)$. Human BDs also have chemotactic activity for memory $\mathrm{T}$ cells and immature dendritic cells through binding to CCR6, thus bridging innate and adaptive immunity $(7,8)$.

In addition to their roles in the innate immune system, several studies have suggested that hBDs are expressed by and have certain roles in some cancer cells. For example, Shestakova et al reported that lung cancer cells express hBD-1, -2 , and -4 $(9,10)$. Arimura et al reported that serum hBD levels are high in lung cancer patients and suggested that hBD-1 could be a new diagnostic marker for lung cancer (11). Markeeva et al revealed that hBD-2 is overexpressed in gastric and cervical cancer cells $(12,13)$, although the level of expression is not correlated with the differentiation grade or stage of the cancer. Mburu et al reported that head and neck squamous cell cancer cells secrete hBD-3. In addition, they found that hBD-3 induces CCR7 expression in these cells in an NF- $\mathrm{BB}$-dependent manner and provides migratory and pro-survival signals to cancer cells (14).

In humans, the number of microbes is highest in the colon, and as such, colon cancer cells would be constantly exposed to a vast number of potential pathogens. Therefore, it is possible that hBDs play specific roles in the development of colon cancer. However, despite several reports suggesting that $\alpha$-defensin is expressed in colon cancer cells (15-17), and that hBD-3, which is induced by microbial stimuli plays a variety of roles in the pathogenesis and progression of head and neck squamous cell and oral squamous cell cancer (OSCC) $(14,18-20)$, little is known about hBD expression in colon cancer cells. In this study, we therefore examined the expression and role of hBD-3 in colon cancer cells.

\section{Materials and methods}

Cell lines and reagents. The human colon cancer cell line COLO-320 (RCB1193) was purchased from the Riken BRC 
Cell Bank (Tsukuba, Japan). The SW480 (ATCC CCL-228), SW620 (ATCC CCL-227), LS180 (ATCC CL-187), and HT29 (ATCC HTB-38) cell lines were purchased from the American Type Culture Collection (Manassas, VA, USA), and the human esophageal cell line KYSE30 (JCRB0188) was purchased from the Health Science Research Resource Bank (Osaka, Japan). All cells were cultured in a humidified atmosphere containing $5 \% \mathrm{CO}_{2}$ at $37^{\circ} \mathrm{C}$ in Dulbecco's modified Eagle's medium (DMEM) (Life Technologies, Tokyo, Japan) supplemented with $1 \%$ penicillin/streptomycin (Life Technologies) and $10 \%$ fetal calf serum (FCS) (Life Technologies).

Human $\beta$-defensin 3 was purchased from the Peptide Institute, Inc. (Osaka, Japan). Lipopolysaccharide (LPS) from E. coli was purchased from Imgenex (San Diego, CA, USA), and LPS from Sallmonella abortus equi was purchased from Enzo Life Science (Farmingdale, NY, USA). Anti-hBD-3 polyclonal antibody was purchased from Phoenix Pharmaceuticals, Inc. (Burlingame, CA, USA).

Qualitative reverse transcriptase-polymerase chain reaction $(P C R)$. The expression of hBD-3 mRNA in colon cancer cells was analyzed by reverse transcriptase-PCR of total RNA. Total RNA was extracted from $\sim 10^{7}$ cells of each cell line using an RNeasy Mini kit (Qiagen, Tokyo, Japan), and cDNA was synthesized by extension of oligo(dT) primers using PrimeScript reverse transcriptase (Takara, Ohtsu, Japan). PCR of the cDNA was performed using Ex Taq (Takara). The primer sets used for amplification of hBD-3 and human GAPDH were as follows: hBD-3 forward, 5'-TTTTGGTGC CTGTTCCAGGT-3' and reverse, 5'-TTCTTCGGCAGCATT TTCGG-3'; human GAPDH forward, 5'-TATAAATTGAGC CCGCAGCC-3' and reverse, 5'-TTCCCGTTCTCAGCCTT GAC-3'.

Immunohistochemistry. Immunohistchemical staining for hBD-3 was performed on surgically resected colon cancer tissues and tissue arrays (Super Bio Chips, Seoul, Korea) using a Vecstain ABC kit (Vector Laboratories, Burlingame, CA, USA). Deparaffinized sections were heated for $5 \mathrm{~min}$ in citrate buffer at $100^{\circ} \mathrm{C}$ with a pressure cooker to reactivate the antigen and then treated with $0.3 \% \mathrm{H}_{2} \mathrm{O}_{2}$ in methanol for $30 \mathrm{~min}$ to deactivate endogenous peroxidases. Sections were blocked with $1 \%$ goat serum in PBS, covered with primary antibody at $4^{\circ} \mathrm{C}$ overnight, covered with second-step biotinylated antibody for $30 \mathrm{~min}$, and then incubated with peroxidase-labeled streptavidin for $30 \mathrm{~min}$. After washing, sections were incubated with $0.05 \%$ diaminobenzidene $/ 0.15 \% \mathrm{H}_{2} \mathrm{O}_{2}$ and counterstained with $10 \%$ hematoxylin (Wako, Osaka, Japan). This study was approved by the Institutional Review Board of Mie University Hospital. Written informed consent was obtained from each patient included in the study. The study protocol conforms to the ethical guidelines of the 1975 Declaration of Helsinki as reflected in a priori approval by the institution's human research committee.

\section{Cell proliferation and viability assays}

MTT assay. Colon cancer cells were plated at a density of $1 \times 10^{4}$ cells per well in 96-well microtiter plates (Corning Glass Works, Corning, NY, USA), and each plate was incubated for $5 \mathrm{~h}$ at $37^{\circ} \mathrm{C}$ in a $5 \% \mathrm{CO}_{2}$ atmosphere. Next, $50 \mu \mathrm{l}$ of hBD-3 or control solution was added to each well, and the plates were incubated for an additional $48 \mathrm{~h}$. The live-cell count was determined using a Cell Titer 96 Assay kit (Promega, Madison, WI, USA) according to the manufacturer's instructions. The absorbance of the contents of each well was measured at $570 \mathrm{~nm}$ with a microtiter plate reader (Bio-Rad Laboratories, Hercules, CA, USA).

$x$ CELLigence system. Cell proliferation and viability was also assessed using an xCELLigence system (Roche Inc., Basel, Switzerland) according to the manufacturer's instructions. Briefly, each well of each 16-well microtiter plate (E-Plate 16) was filled with $100 \mu 1$ of DMEM to equilibrate the well membrane, and the plates were then incubated for $30 \mathrm{~min}$ at $37^{\circ} \mathrm{C}$ in a $5 \% \mathrm{CO}_{2}$ atmosphere. Colon cancer cells suspended in $50 \mu 1$ of growth medium were seeded at a density of $1 \times 10^{4}$ cells per well, and $50 \mu \mathrm{l}$ of hBD-3 solution was added $6 \mathrm{~h}$ later. Cells were cultured for $48 \mathrm{~h}$ using a Real-Time Cell Analyzer (RTCA) single plate (SP) instrument placed in a standard incubator at $37^{\circ} \mathrm{C}$ in a $5 \% \mathrm{CO}_{2}$ atmosphere. Cell index values were monitored and recorded at 15 -min intervals.

Migration assay. Changes in the migration of SW480 and SW620 cells were analyzed using a fibronectin-coated Oris Cell Migration Assay kit (Platypus Technologies, Madison, WI, USA) according to the manufacturer's protocol. Briefly, cells were plated at a density of $1 \times 10^{4}$ cells per well and incubated at $37^{\circ} \mathrm{C}$ in a $5 \% \mathrm{CO}_{2}$ atmosphere. After $24 \mathrm{~h}$, all the stoppers were removed from the wells and the cells were washed once and the medium was exchanged with medium containing various concentrations of hBD-3 $(0,1$ or $5 \mu \mathrm{M})$. After an additional $24 \mathrm{~h}$ of incubation, the wells were photographed and cell migration was analyzed using ImageJ software (US National Institutes of Health).

Real-time PCR array. Changes in the expression of genes related to the migration and invasiveness of SW480 and SW620 cells following exposure to hBD-3 $(5 \mu \mathrm{M})$ were analyzed using an RT ${ }^{2}$ PCR array (Human Extracellular Matrix and Adhesion Molecules) (SABiosciences Corp., Frederick, MD, USA) according to the manufacturer's instructions. Observed changes in mRNA expression were confirmed using quantitative real-time PCR.

Quantitative real-time PCR. cDNAs of colon cancer cell lines were synthesized from $1 \mu \mathrm{g}$ of total RNA. Quantitative real-time PCR (qRT-PCR) was performed using an ABI PRISM 7300 Real-time PCR system (Applied Biosystems, Foster City, CA, USA) with EagleTaq Master Mix kits (Roche Molecular Systems, Branchburg, NJ, USA). The expression levels of target genes were determined from triplicate reactions by normalization of expression data to that of $\beta$-actin according to the manufacturer's instructions. The primer set and probe for metastasis-associated 1 family, member 2 (MTA2) were as follows: sense primer, 5'-CGCAGGGACATTTCTAGTAGC-3'; antisense primer, 5'-GCTGCTTTGATTCCTCTTCAAA-3'; probe, CAGCCTGG.

Statistical analysis. Cell proliferation, migration, and gene expression data were compared using the two-tailed Student's 


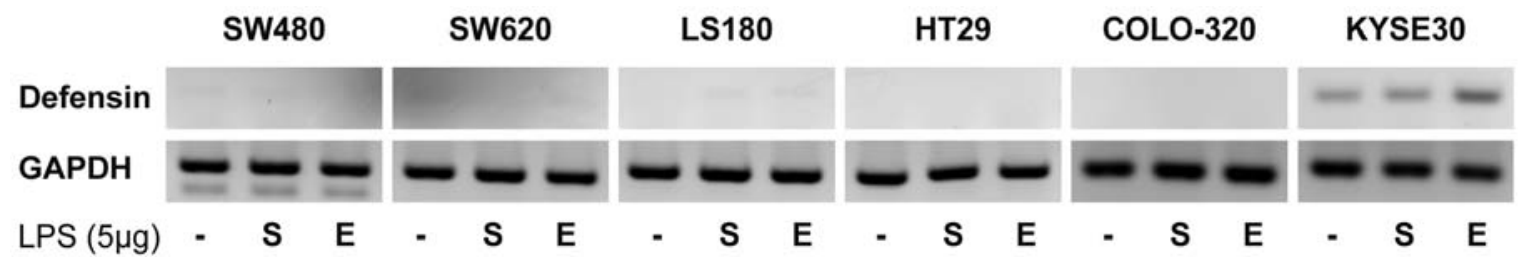

Figure 1. Detection of hBD-3 mRNA. The expression of hBD-3 was examined in colon cancer cell lines using qualitative RT-PCR. None of the colon cancer cell lines were positive for hBD-3 mRNA. However, KYSE30 human esophageal cancer cells expressed hBD-3 mRNA, and the level of expression was increased by addition of LPS. S, LPS from Sallmonella abortus equi. E, LPS from E. coli.

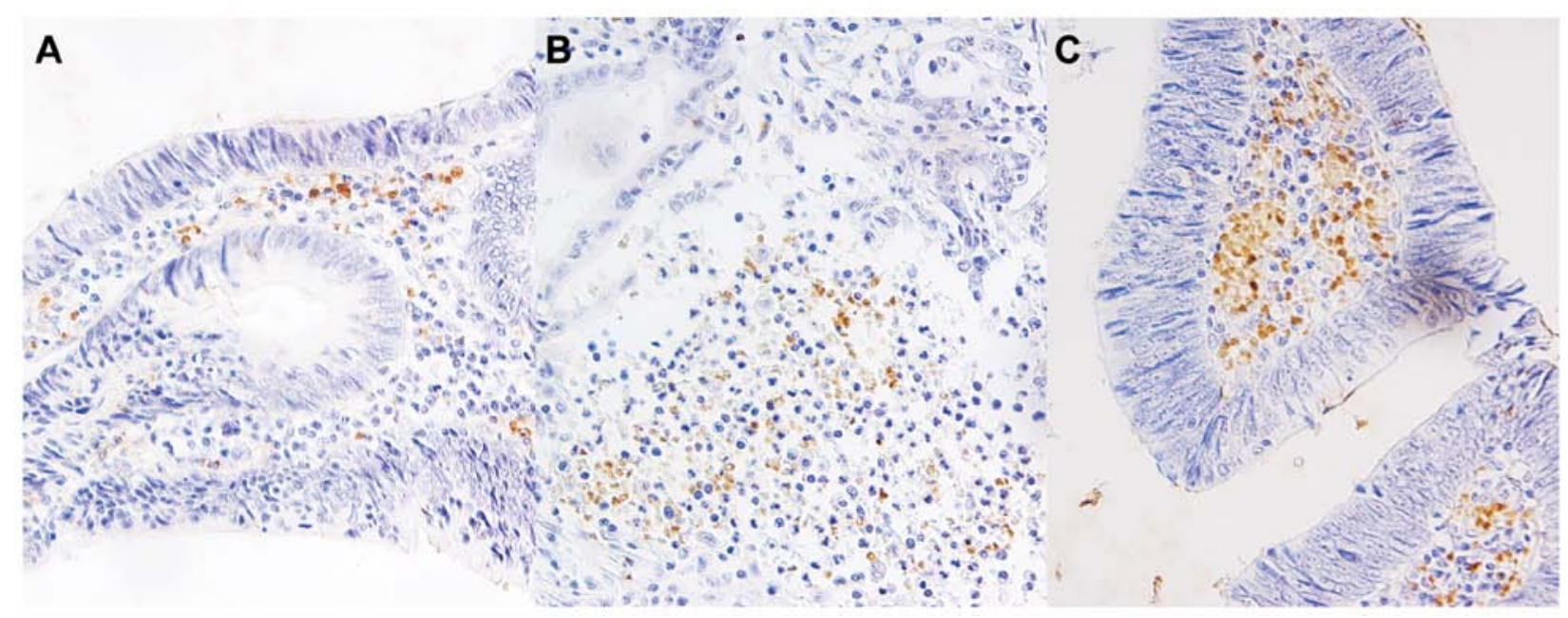

Figure 2. Immunohistochemical staining for hBD-3 in surgically resected colon cancer tissues. Colon cancer cells were not positive for hBD-3; however, in some tissues, infiltrating monocytes showed strong positive staining for hBD-3. (A) Low expression of hBD-3; (B) moderate expression of hBD-3; (C) high expression of hBD-3. Original magnification, $\mathrm{x} 200$.

t-test. For differences between rates, Fisher's exact test was used. A P-value $<0.05$ was considered statistically significant.

\section{Results}

Human BD-3 mRNA is not expressed in colon cancer cells. First, we examined hBD-3 mRNA expression in each colon cancer cell line by qualitative reverse transcriptase-PCR. No hBD-3 transcripts were detected in any of the colon cancer cell lines examined (SW480, SW620, LS180, HT29 and COLO-320), and LPS stimulation had no effect on hBD-3 mRNA expression in these cell lines. In contrast, KYSE30 esophageal cancer cells did express hBD-3 mRNA, the level of which increased with LPS stimulation (Fig. 1).

Human BD-3 is expressed in infiltrating monocytes of colon cancer tissues. Next, we performed immunohistochemical staining for hBD-3 in surgically resected colon cancer tissues. No hBD-3 expression was detected in the colon cancer cells; however, many tissue samples stained positive for hBD-3 in infiltrating monocytes surrounding the cancer cells (Fig. 2). Similar results were obtained by immunohistochemical staining of tissue array samples. Results of the immunohistochemistry analyses are summarized in Table I. The level of hBD-3 expression was analyzed in each group, and the percentage of positive-staining stromal monocytes was divided into three categories (0-33, 34-66 and 67-100\%). No
Table I. Summary of immunohistochemical staining results.

\begin{tabular}{|c|c|c|c|c|}
\hline & \multirow[b]{2}{*}{ Cases (n) } & \multicolumn{3}{|c|}{ Extent of positive staining } \\
\hline & & $0-33 \%$ & $34-66 \%$ & $67-100 \%$ \\
\hline Total & 39 & $7(17.9 \%)$ & $24(61.5 \%)$ & $8(20.1 \%)$ \\
\hline $\begin{array}{l}\text { Well } \\
\text { differentiated }^{\text {a }}\end{array}$ & 9 & $2(22.2 \%)$ & $4(44.4 \%)$ & $3(33.3 \%)$ \\
\hline $\begin{array}{l}\text { Moderately } \\
\text { differentiated }\end{array}$ & 26 & $4(15.4 \%)$ & $17(65.4 \%)$ & $5(19.2 \%)$ \\
\hline $\begin{array}{l}\text { Poorly } \\
\text { differentiated }\end{array}$ & 1 & $1(100 \%)$ & $0 \quad(0 \%)$ & $0 \quad(0 \%)$ \\
\hline
\end{tabular}

${ }^{a}$ Well, moderately and poorly refer to the status of colon cancer differentiation.

correlation was found between the degree of positive staining for hBD-3 and the degree of cancer cell differentiation, possibly due to the small number of well differentiated and poorly differentiated colon cancer tissues.

Human BD-3 does not affect the proliferation of colon cancer cells. To assess how hBD-3 affects colon cancer cells, we first 

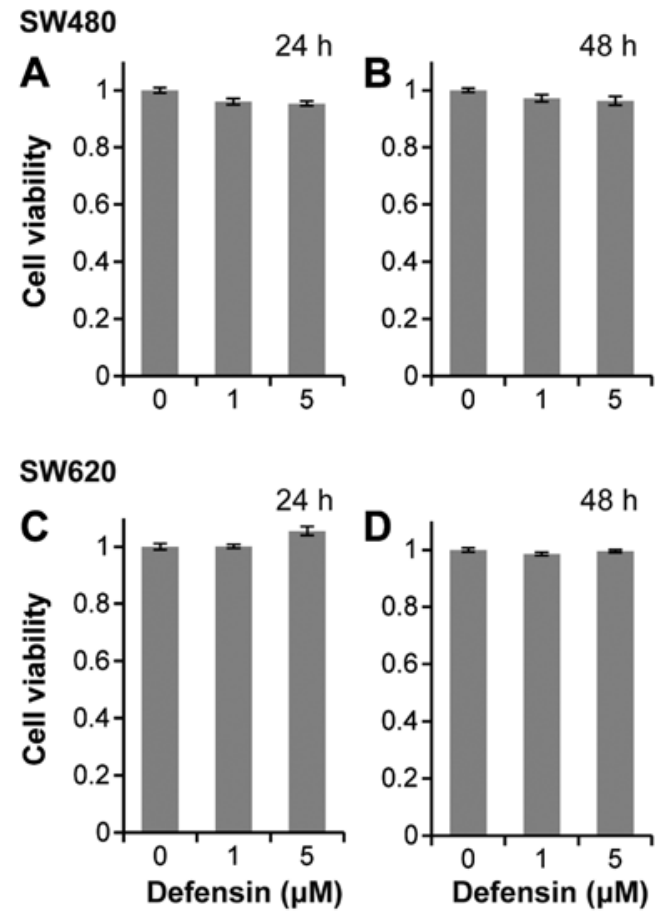

Figure 3. Effect of hBD-3 on colon cancer cell proliferation. SW420 cells were co-cultured with various concentrations of $\mathrm{hBD}-3$, and cell proliferation was assessed using the MTT assay after (A) 24 and (B) $48 \mathrm{~h}$. The effect of hBD-3 exposure on SW620 cells was also assessed after (C) 24 and (D) $48 \mathrm{~h}$. Cancer cell proliferation was determined relative to control cells. Data are expressed as means \pm SEM.
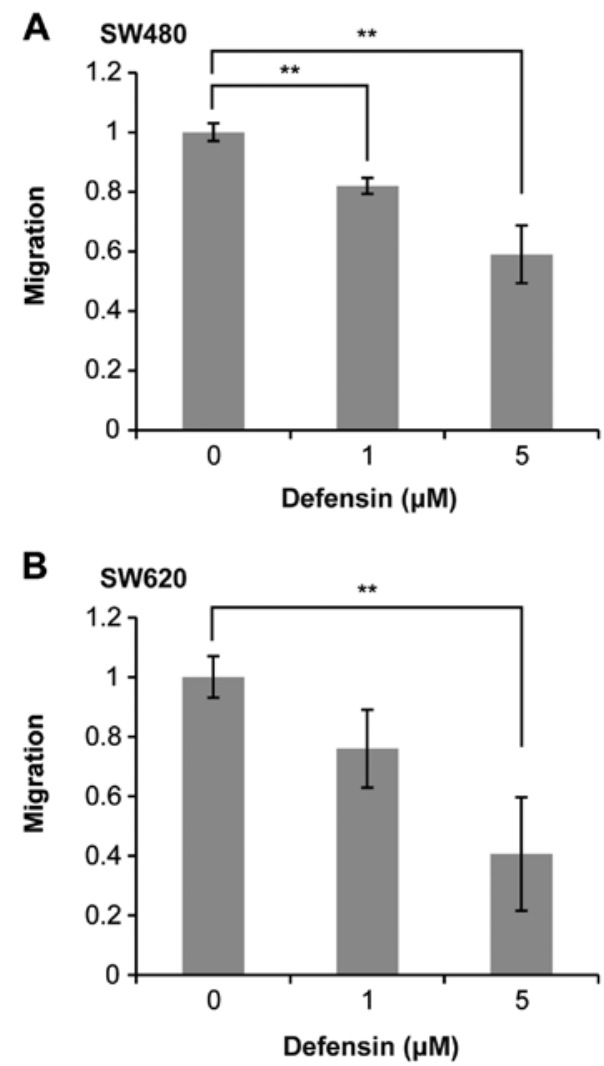

Figure 4. Effect of hBD-3 on colon cancer cell migration. (A) SW420 and (B) SW620 cells were cultured with various concentrations of hBD-3 (1 or $5 \mu \mathrm{M})$, and cell migration was assessed using a fibronectin-coated Oris Cell Migration Assay kit after $24 \mathrm{~h}$. Data are expressed as means \pm SEM relative to control cells $\left({ }^{*} \mathrm{P}<0.05,{ }^{* *} \mathrm{P}<0.01\right)$.
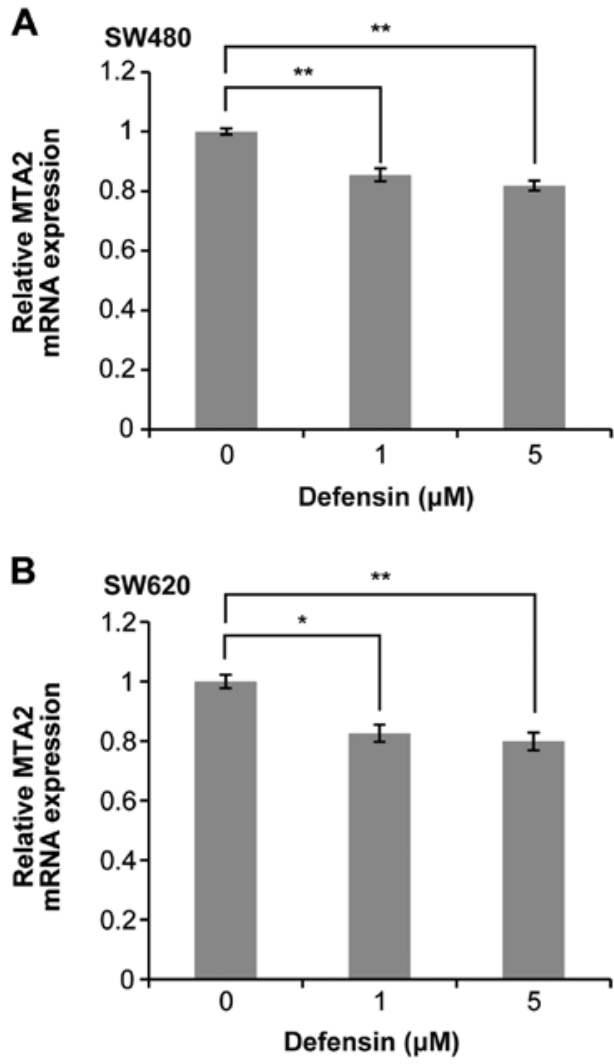

Figure 5. Expression of MTA2 mRNA following exposure of colon cancer cells to hBD-3. The level of MTA2 mRNA expression in (A) SW480 and (B) SW620 cells decreased significantly in a dose-dependent manner following exposure to hBD-3. Data are expressed as means \pm SEM relative to control cells $\left({ }^{*} \mathrm{P}<0.05,{ }^{* *} \mathrm{P}<0.01\right)$.

examined the effect of hBD-3 on cancer cell proliferation using an MTT assay and the xCELLigence system. Fig. 3 shows the results of the MTT assay after 24 and $48 \mathrm{~h}$. Proliferation of SW480 and SW620 cells was not affected by exposure to hBD-3 at concentrations of 1 and $5 \mu \mathrm{M}$. Similar results were obtained with the xCELLigence system (data not shown).

Human BD-3 inhibits the migration of colon cancer cells. Next, we examined the effect of hBD-3 on colon cancer cell migration. Interestingly, as shown in Fig. 4A, co-culture with hBD-3 (1 or $5 \mu \mathrm{M})$ significantly inhibited the migration of SW480 cells after $24 \mathrm{~h}$ in a dose-dependent manner. A similar inhibition of migration following exposure to hBD-3 was observed in SW620 cells (Fig. 4B).

Human BD-3 reduces MTA2 $\mathrm{mRNA}$ expression in colon cancer cells. To elucidate the mechanism through which hBD-3 suppresses the migration of colon cancer cells, we compared the expression of MTA2 mRNA in SW480 cells co-cultured with $5 \mu \mathrm{M}$ hBD-3 and control cells using a real-time PCR array. This experiment was repeated twice, and the results of both experiments showed that the expression of MTA2 was reduced by addition of hBD-3 to the culture medium (data not shown). To confirm these results, we examined hBD-3induced changes in the level of MTA2 mRNA expression in colon cancer cells using qRT-PCR. As shown in Fig. 5, the level of MTA2 mRNA expression was significantly reduced 
in both SW480 and SW620 cells in a dose-dependent manner following exposure to hBD-3.

\section{Discussion}

In the present study, we demonstrated that hBD-3 is not expressed in colon cancer cells but is expressed in tumorinfiltrating monocytes. Migration of cells of various colon cancer lines was significantly inhibited by exposure to hBD-3, although hBD-3 had no effect on proliferation of these cells. Moreover, reduced expression of MTA 2 mRNA in colon cancer cells was associated with exposure to hBD-3.

Accumulating evidence indicates that several types of epithelial and cancer cells produce hBD-3. It was reported that hBD-3 is expressed in the skin, oral cavity, esophagus, trachea and placenta $(5,21)$. Moreover, gastric and colon epithelial cells produce a large amount of hBD-3 in response to chronic inflammation $(22,23)$. Expression of hBDs has been reported in lung cancer, head and neck cancer, and OSCC $(9,10,14,18-20)$. However, the significance of the expression of hBDs in cancer cells is still controversial; for example, the expression of hBD-1 and hBD-3 is lost at a high frequency in prostate cancer, renal cell carcinoma and OSCC (24-28). Initially, we hypothesized that colon cancer cells themselves produce hBD-3 because these cells are constantly exposed to many microorganisms. However, our results demonstrate that hBD-3 is not expressed in cells of various colon cancer lines, nor is it expressed in surgically resected colon cancer cells. Furthermore, we found that hBD-3 mRNA expression is not affected by the presence of bacterial LPS, which was reported to upregulate hBD-3 expression in OSCC (29).

Although our results indicate that colon cancer cells do not produce hBD-3, immunohistochemical staining showed that tumor-infiltrating monocytes express high levels of hBD-3. As we supposed that colon cancer cells are exposed to hBD-3 excreted by monocytes, we next investigated the effects of hBD-3 on colon cancer progression. The results of our functional assays showed that hBD-3 significantly suppresses the migration of colon cancer cells. An increasing number of studies have suggested that defensins play important roles in modulating the development and progression of several kinds of cancers. $\mathrm{Xu}$ et al showed that intratumoral administration of $\alpha$-defensin- 1 inhibits the growth of human lung adenocarcinoma xenografts in nude mice, inducing apoptosis of these cells (30). Several studies have suggested that hBD-3 enhances progression of oral and head squamous carcinomas $(14,20,29)$. However, Wang et al reported that hBD-3 inhibits the migration of head and neck cancer cells (18), and our results agree with their data.

The addition of hBD-3 to the culture medium of colon cancer cell lines significantly reduced the expression of MTA2 mRNA in the current study. MTA2 is a member of the metastasis-associated family of proteins, which includes MTA1, MTA2, and MTA3. MTA1 was the first of these proteins to be identified, and there have been many reports demonstrating that MTA1 overexpression is closely correlated with carcinogenesis and the progression of a wide range of solid human cancers, including breast, liver, lung, gastric and colorectal (31-34). MTA2 is highly homologous to MTA1 and is a component of the nucleosome remodeling and histone deacetylase (NuRD) complex $(35,36)$. Several studies have also reported that there is a relationship between MTA2 expression and a higher degree of malignant potential for various cancers (35,37-41). All of these reports indicate that MTA2 drives carcinogenesis and enhances tumor invasiveness. Recent studies have provided insight into how MTA proteins may enhance cancer progression. Cui et al reported that the NuRD complex represses the transactivation function of estrogen receptor- $\alpha$, causing breast cancer cells to become more aggressive (42). Luo et al found that the NuRD complex also deacetylates and thus inactivates $\mathrm{p} 53$, a protein that mediates cell growth arrest and apoptosis (43). Our findings suggest that hBD-3 inhibits the migration of colon cancer cells by downregulating MTA2 expression.

Probably one of the most important findings of this study is that hBD-3 has a suppressive effect on colon cancer. However, we acknowledge that our experimental data were obtained from cultured cell lines, and we did not clarify whether any relationship exists between prognosis and hBD-3 expression in either cancer cells or stromal monocytes in colon cancer tissues; therefore, further investigation is required. Also, the precise mechanism through which hBD-3 downregulates MTA2 expression remains to be elucidated.

In conclusion, our present study demonstrates that hBD-3 inhibits the progression of colon cancer in a paracrine fashion. We believe that hBD-3 will prove to be a potent new addition to the therapeutic arsenal for treating colon cancer.

\section{References}

1. Raj PA and Dentino AR: Current status of defensins and their role in innate and adaptive immunity. FEMS Microbiol Lett 206: 9-18, 2002.

2. Ganz T: Defensins: antimicrobial peptides of innate immunity. Nat Rev Immunol 3: 710-720, 2003.

3. Yang D, Biragyn A, Hoover DM, Lubkowski J and Oppenheim JJ: Multiple roles of antimicrobial defensins, cathelicidins, and eosinophil-derived neurotoxin in host defense. Annu Rev Immunol 22: 181-215, 2004.

4. Schutte BC, Mitros JP, Bartlett JA, et al: Discovery of five conserved beta-defensin gene clusters using a computational search strategy. Proc Natl Acad Sci USA 99: 2129-2133, 2002.

5. Jia HP, Schutte BC, Schudy A, et al: Discovery of new human beta-defensins using a genomics-based approach. Gene 263: 211-218, 2001.

6. Sorensen OE, Thapa DR, Rosenthal A, Liu L, Roberts AA and Ganz T: Differential regulation of beta-defensin expression in human skin by microbial stimuli. J Immunol 174: 4870-4879, 2005.

7. Zlotnik A and Yoshie O: Chemokines: a new classification system and their role in immunity. Immunity 12: 121-127, 2000.

8. Wu Z, Hoover DM, Yang D, et al: Engineering disulfide bridges to dissect antimicrobial and chemotactic activities of human beta-defensin 3. Proc Natl Acad Sci USA 100: 8880-8885, 2003.

9. Shestakova T, Zhuravel E, Bolgova L, Alekseenko O, Soldatkina $M$ and Pogrebnoy P: Expression of human betadefensins-1, 2 and 4 mRNA in human lung tumor tissue: a pilot study. Exp Oncol 30: 153-156, 2008.

10. Shestakova T,Zhuravel E, Bolgova L, et al: Immunohistochemical analysis of beta-defensin-2 expression in human lung tumors. Exp Oncol 32: 273-276, 2010.

11. Arimura Y, Ashitani J, Yanagi S, et al: Elevated serum betadefensins concentrations in patients with lung cancer. Anticancer Res 24: 4051-4057, 2004.

12. Markeeva N, Lisovskiy I, Lyzogubov V, et al: Expression of betadefensin-2 in human gastric tumors: a pilot study. Exp Oncol 27: 130-135, 2005.

13. Markeeva N, Lysovskiy I, Zhuravel E, et al: Involvement of human beta-defensin-2 in proliferation of transformed cells of human cervix. Exp Oncol 27: 308-313, 2005. 
14. Mburu YK, Abe K, Ferris LK, Sarkar SN and Ferris RL: Human beta-defensin 3 promotes NF-kappaB-mediated CCR7 expression and anti-apoptotic signals in squamous cell carcinoma of the head and neck. Carcinogenesis 32: 168-174, 2010.

15. Melle C, Ernst G, Schimmel B, et al: Discovery and identification of alpha-defensins as low abundant, tumor-derived serum markers in colorectal cancer. Gastroenterology 129: 66-73, 2005.

16. Albrethsen J, Bogebo R, Gammeltoft S, Olsen J, Winther B and Raskov H: Upregulated expression of human neutrophil peptides 1, 2 and 3 (HNP 1-3) in colon cancer serum and tumours: a biomarker study. BMC Cancer 5: 8, 2005.

17. Albrethsen J, Moller CH, Olsen J, Raskov H and Gammeltoft S: Human neutrophil peptides 1,2 and 3 are biochemical markers for metastatic colorectal cancer. Eur J Cancer 42: 3057-3064, 2006.

18. Wang K, Wang JH, Baskaran H, Wang R and Jurevic R: Effect of human beta-defensin-3 on head and neck cancer cell migration using micro-fabricated cell islands. Head Neck Oncol 4: 41, 2012 .

19. Kawsar HI, Weinberg A, Hirsch SA, et al: Overexpression of human beta-defensin-3 in oral dysplasia: potential role in macrophage trafficking. Oral Oncol 45: 696-702, 2009.

20. Winter J, Pantelis A, Reich R, et al: Human beta-defensin-1, -2, and -3 exhibit opposite effects on oral squamous cell carcinoma cell proliferation. Cancer Invest 29: 196-201, 2011.

21. Harder J, Bartels J, Christophers E and Schroder JM: Isolation and characterization of human beta-defensin-3, a novel human inducible peptide antibiotic. J Biol Chem 276: 5707-5713, 2001.

22. Kawauchi K, Yagihashi A, Tsuji N, et al: Human beta-defensin-3 induction in $H$. pylori-infected gastric mucosal tissues. World $\mathrm{J}$ Gastroenterol 12: 5793-5797, 2006.

23. Fahlgren A,Hammarstrom S, Danielsson A and Hammarstrom ML: beta-Defensin-3 and -4 in intestinal epithelial cells display increased mRNA expression in ulcerative colitis. Clin Exp Immunol 137: 379-385, 2004.

24. Donald CD, Sun CQ, Lim SD, et al: Cancer-specific loss of beta-defensin 1 in renal and prostatic carcinomas. Lab Invest 83: 501-505, 2003

25. Young AN, de Oliveira Salles PG, Lim SD, et al: Beta defensin-1, parvalbumin, and vimentin: a panel of diagnostic immunohistochemical markers for renal tumors derived from gene expression profiling studies using cDNA microarrays. Am J Surg Pathol 27 199-205, 2003.

26. Bullard RS, Gibson W, Bose SK, et al: Functional analysis of the host defense peptide Human Beta Defensin-1: new insight into its potential role in cancer. Mol Immunol 45: 839-848, 2008

27. Joly S, Compton LM, Pujol C, Kurago ZB and Guthmiller JM: Loss of human beta-defensin 1,2, and 3 expression in oral squamous cell carcinoma. Oral Microbiol Immunol 24: 353-360, 2009.

28. Yoshimoto T, Yamaai T, Mizukawa N, et al: Different expression patterns of beta-defensins in human squamous cell carcinomas. Anticancer Res 23: 4629-4633, 2003.
29. Shuyi Y, Feng W, Jing T, et al: Human beta-defensin-3 (hBD-3) upregulated by LPS via epidermal growth factor receptor (EGFR) signaling pathways to enhance lymphatic invasion of oral squamous cell carcinoma. Oral Surg Oral Med Oral Pathol Oral Radiol Endod 112: 616-625, 2011.

30. Xu N, Wang YS, Pan WB, et al: Human alpha-defensin-1 inhibits growth of human lung adenocarcinoma xenograft in nude mice. Mol Cancer Ther 7: 1588-1597, 2008.

31. Toh Y, Oki E, Oda S, et al: Overexpression of the MTA1 gene in gastrointestinal carcinomas: correlation with invasion and metastasis. Int J Cancer 74: 459-463, 1997.

32. Martin MD, Fischbach K, Osborne CK, Mohsin SK, Allred DC and O'Connell P: Loss of heterozygosity events impeding breast cancer metastasis contain the MTA1 gene. Cancer Res 61: 3578-3580, 2001

33. Hamatsu T, Rikimaru T, Yamashita Y, et al: The role of MTA1 gene expression in human hepatocellular carcinoma. Oncol Rep 10: 599-604, 2003.

34. Sasaki H, Moriyama S, Nakashima Y, et al: Expression of the MTA1 mRNA in advanced lung cancer. Lung Cancer 35: 149-154, 2002

35. Zhang Y, Ng HH, Erdjument-Bromage H, Tempst P, Bird A and Reinberg D: Analysis of the NuRD subunits reveals a histone deacetylase core complex and a connection with DNA methylation. Genes Dev 13: 1924-1935, 1999.

36. Toh Y and Nicolson GL: The role of the MTA family and their encoded proteins in human cancers: molecular functions and clinical implications. Clin Exp Metastasis 26: 215-227, 2009.

37. Ji Y, Zhang P, Lu Y and Ma D: Expression of MTA2 gene in ovarian epithelial cancer and its clinical implication. J Huazhong Univ Sci Technolog Med Sci 26: 359-362, 2006.

38. Lee H, Ryu SH, Hong SS, et al: Overexpression of metastasisassociated protein 2 is associated with hepatocellular carcinoma size and differentiation. J Gastroenterol Hepatol 24: 1445-1450, 2009.

39. Liu SL, Han Y, Zhang Y, et al: Expression of metastasis-associated protein 2 (MTA2) might predict proliferation in non-small cell lung cancer. Target Oncol 7: 135-143, 2012.

40. Covington KR, Brusco L, Barone I, et al: Metastasis tumor-associated protein 2 enhances metastatic behavior and is associated with poor outcomes in estrogen receptor-negative breast cancer. Breast Cancer Res Treat 141:375-384, 2013.

41. Zhou C, Ji J, Cai Q, et al: MTA2 promotes gastric cancer cells invasion and is transcriptionally regulated by Sp1. Mol Cancer 12: 102, 2013

42. Cui Y, Niu A, Pestell R, et al: Metastasis-associated protein 2 is a repressor of estrogen receptor alpha whose overexpression leads to estrogen-independent growth of human breast cancer cells. Mol Endocrinol 20: 2020-2035, 2006.

43. Luo J, Su F, Chen D, Shiloh A and Gu W: Deacetylation of p53 modulates its effect on cell growth and apoptosis. Nature 408: 377-381, 2000 . 